\title{
Article \\ Effect of Ni Doping on the Embrittlement of Liquid Zinc at $\Sigma 5$ Fe Austenite Grain Boundary
}

\author{
Chengfa Ding ${ }^{1}$, Wangjun Peng ${ }^{2}$, Zheng Ma ${ }^{1}$, Yan Zhao ${ }^{1, *}$, Huaxiang Teng ${ }^{3}$ and Guangxin $\mathrm{Wu}^{1, *}$ \\ 1 School of Materials Science and Engineering \& State Key Laboratory of Advanced Special Steel \& Shanghai \\ Key Laboratory of Advanced Ferrometallurgy, Shanghai University, Shanghai 200072, China; \\ dingchengfa@shu.edu.cn (C.D.); MaZheng2020@shu.edu.cn (Z.M.) \\ 2 School of Materials Science and Engineering, Shanghai Dianji University, Shanghai 201306, China; \\ pengwj@sdju.edu.cn \\ 3 Shougang Research Institute of Technology, Shougang Group Co., Ltd., Beijing 100043, China; \\ tenghuaxiang@shougang.com.cn \\ * Correspondence: zhaoyan8626@shu.edu.cn (Y.Z.); gxwu@shu.edu.cn (G.W.)
}

Citation: Ding, C.; Peng, W.; Ma, Z.; Zhao, Y.; Teng, H.; Wu, G. Effect of Ni Doping on the Embrittlement of Liquid Zinc at $\Sigma 5$ Fe Austenite Grain Boundary. Metals 2022, 12, 27. https://doi.org/10.3390/met12010027

Academic Editor: Zhongchang Wang

Received: 10 November 2021

Accepted: 16 December 2021

Published: 23 December 2021

Publisher's Note: MDPI stays neutral with regard to jurisdictional claims in published maps and institutional affiliations.

Copyright: (c) 2021 by the authors. Licensee MDPI, Basel, Switzerland. This article is an open access article distributed under the terms and conditions of the Creative Commons Attribution (CC BY) license (https:// creativecommons.org/licenses/by/ $4.0 /)$.

\begin{abstract}
In this study, first-principles computational tensile tests have been performed for the $\Sigma 5$ symmetrically tilted grain boundaries of the face-centered cubic (fcc) Fe to investigate the effects of $\mathrm{Zn}$ and $\mathrm{Zn}-\mathrm{Ni}$ doping on the boundary energy and electronic structure. The obtained results indicate that the mismatch between the sizes of $\mathrm{Zn}$ and Fe atoms at the $\mathrm{Zn}$-doped grain boundary causes its expansion, which increases the lengths of Fe-Fe bonds, leading to their weakening, and reduces the overall boundary strength. After the $\mathrm{Zn}$ doping of the Fe grain boundary, $\mathrm{Zn}$ atoms form covalent bonds with Fe atoms, that decreases the charge density of Fe-Fe bonds and their strength. Meanwhile, the strength of the newly formed Fe-Zn covalent bonds oriented at a certain angle with respect to the grain boundary direction is very low. The breakage of Fe-Fe bonds that occurs under tensile loading rapidly decreases the boundary strength. Finally, after the Zn-Ni co-doping of the Fe grain boundary, $\mathrm{Ni}$ atoms form metallic bonds with Fe atoms, thus increasing both the charge density of Fe-Fe bonds (as compared with that of the Fe-Fe bonds at the $\mathrm{Zn}$-doped grain boundary).
\end{abstract}

Keywords: first-principles computational tensile test; $\Sigma 5$ [001] (210) 53.6 fcc Fe symmetrically tilted grain boundary; liquid zinc-induced embrittlement; Zn-Ni co-doping

\section{Introduction}

High-strength steel can be effectively manufactured by hot forming technology, which prevents its oxidation and decarburization during production and significantly increases the corrosion resistance. However, the macro and micro cracks formed in the high-strength steel structure due to the low melting point of zinc-based coatings and liquid zinc-induced embrittlement considerably limit the applications of hot forming processes [1-4].

By optimizing the austenite processing or forming conditions, it is possible to avoid the occurrence of matrix cracking [5-8]. Although many researchers examined the related experimental parameters, they have not investigated the effect produced by the liquid metal-induced brittleness on a microscopic scale, which can be achieved by performing first-principles calculations. Bauer et al. [9] established $\Sigma 3$ [110] $60^{\circ}$ and $\Sigma 5$ [100] 36.8 ${ }^{\circ}$ symmetrically tilted grain boundary (GB) models of the body-centered cubic (bcc) Fe structure to evaluate the changes in the grain boundary and surface energies before and after zinc doping. Furthermore, two thermodynamic models (the Rice-Wang and Griffith models) were developed to estimate the energy of the grain boundary embrittlement caused by doping the bcc Fe structure with $\mathrm{Zn}$ atoms.

In addition to the energy characterizations of the embrittlement and strengthening effects produced by the presence of impurities at grain boundaries, first-principles tensile test of the grain boundaries doped with impurities were performed to study the influences of the chemical bonds and electronic structures of these impurities on the boundary 
properties [10-13]. Thus, Yuasa et al. [14,15] used first-principles stretching methods to identify the causes of the brittle fracture of a $\Sigma 3$ (111) grain boundary in the bcc Fe lattice doped with $\mathrm{P}$ and $\mathrm{Cu}$ elements. They found that the tensile strength and elongation of this boundary decreased after doping, indicating significant deterioration of its mechanical characteristics. Miyazawa et al. [10] conducted first-principles fully relaxed tensile tests that were performed on a C-segregated Fe $\Sigma 3(111) /[1 \overline{1} 0]$ symmetrical tilt grain boundary to investigate the breaking behaviour of $\mathrm{C}$-Fe bonds during tensile straining. The results revealed that the $\mathrm{C}$-Fe bonds showed a high bond mobility.

To determine the effect of austenite grain boundaries on the diffusion of zinc atoms, these boundaries were examined in detail. According to the results of previous studies, the original austenitized grain boundaries can be reconstructed from electron backscatter diffraction (EBSD) data by two methods, including a complex algorithm of Nyyssönen et al. [16] and a simpler method developed by Hutchinson et al. [17] In the second method, the grain boundaries of the martensite structure after the phase transformation contain low-angle grain boundaries (LABs) or $50-63^{\circ}$ grain boundary [18]. Before the martensite phase transformation that occurs during the cooling cycle of a welding process, the liquid metal-induced embrittlement (LMIE) cracks propagate along the high-angle grain boundaries (HABs) of the original austenite structure and not along martensitic grain boundaries. However, after the martensite formation, LMIE cracks tend to propagate along the martensitic grain boundaries because of the stress concentration at the crack tip [19].

Twinning-induced plasticity steel contains a large number of twins with the $\Sigma 3$ $\left(60^{\circ}[111]\right)$ orientational relationship [20,21]. Zinc diffusion through cracks occurs only at $\mathrm{HABs}$, and cracks are not formed at LABs. In addition, the statistical results of the grain orientation difference of zinc penetrating the original grain boundary also show that $60^{\circ}$ is the main crack location. Therefore, it can be hypothesized that $\Sigma 3$ HABs play an important role in the diffusion of zinc atoms along the grain boundary [22].

The mechanism of the liquid zinc-induced embrittlement in steels has not been elucidated yet. The obtained experimental data suggested that the developed fracture model was applicable only to the cracking of the ferrite phase formed by the presence of $\mathrm{Zn}$ atoms near the austenite grain boundaries [23-25]. However, multiple theoretical studies on the cracking of ferrite grain boundaries have been conducted by first-principles calculations. Peng et al. [26] used the first-principles computational tensile test (FPCTT) to study the liquid-zinc-induced embrittlement in the $\Sigma 5$ [100] $36.8^{\circ}$ symmetric tilt grain boundary (STGB) of bcc Fe. The result reveals that the strength and ductility of the grain boundary (GB) decrease after zinc doping. In addition, the effect of zinc on the chemical bond and electronic structure of the GB is investigated. However, Peng et al. [26] only considers the infiltration process of liquid zinc at the ferrite grain boundary, and in fact, austenite grain boundary also plays an important role in grain boundary embrittlement. Bhattacharya et al. [27] reported that twinning-induced plasticity (TWIP) steels, having an austenitic microstructure, exhibit greater LMIE susceptibility compared to TRIP-assisted bainitic ferrite (TBF) or ferrite-martensite dual phase (DP) steels. Cho et al. [28] analyzed the microstructure of the intergranular liquid-metal-induced cracks and proposed a new model for crack formation. Intergranular cracking is due to the grain boundary penetration of a liquid $\mathrm{Zn}$ alloy phase along a crack tip propagating on prior austenite grain boundaries weakened by the Zn diffusion-mitigated phase transformation to ferrite. Kang et al. [29] believed that during high temperature processing of austenitic TWIP steel, As a result of Zn accumulation in the grain boundary, $\mathrm{Zn}$ content exceeds the maximum solubility limit in austenite. Over the maximum solubility limit, liquid-Zn starts to form along the austenite grain boundaries. Afterwards, as a consequence of liquid-Zn film presence along grain boundaries, the metallic bond weakening takes place, and subsequently, the initial LMIE crack opens up. Thus, the importance of austenite grain boundary in the embrittlement induced by liquid zinc is obvious. However, there are few studies on the embrittlement of austenite grain boundaries induced by liquid zinc. 
Therefore, in this study, first-principles computational tensile tests were performed on Zn-embrittled austenite grain boundaries. Using the $\Sigma 5$ [001] (210) $53.6^{\circ}$ face-centered cubic (fcc) Fe symmetrically tilted grain boundary model and the corresponding doped grain boundary models, the effects produced by introducing $\mathrm{Zn}$ and $\mathrm{Zn}$-Ni elements were analyzed. In particular, the changes in the atomic and electronic structures caused by grain boundary doping were determined to elucidate the Zn-assisted embrittlement mechanism and influence of $\mathrm{Ni}$ atoms on the grain boundary properties after $\mathrm{Zn}$ replacement.

\section{Experimental Methods}

\subsection{Grain Boundary Models}

The match between the calculated and experimental results determines the accuracy of a utilized simulation method. Hence, combining theory with experiment can help better explain experimental phenomena. The most important aspect of first-principles calculations is the establishment of a suitable model and selection of calculation parameters. In this section, using the grain boundary characteristics obtained from the literature and by the EBSD scanning of the crack tip region $[18,19]$, an appropriate grain boundary model is established to further explain the brittle fracture induced by liquid zinc.

The zinc-based coating hot-formed steel QP1180 was selected and heated to the target temperature of $900{ }^{\circ} \mathrm{C}$ at a heating rate of $20^{\circ} \mathrm{C} \cdot \mathrm{s}^{-1}$ in the Gleeble 3500 thermomechanical simulator, and kept for $10 \mathrm{~min}$. Then the strain was performed at a strain rate of $0.5 \mathrm{~s}^{-1}$. After the strain is over, compressed air is used to quench the steel plate at a cooling rate exceeding $50^{\circ} \mathrm{C} \cdot \mathrm{s}^{-1}$. To determine the Fe grain boundary type near the crack tip, EBSD (Zeiss Gemini SEM 450, Germany) scannings were performed in the vicinity of the side crack on the substrate (see Figure 1). The acceleration voltage of the scanning electron microscope was $25 \mathrm{kV}$, and the spot size was 5. A hexagonal grid with a step size of $250 \mathrm{~nm}$ was used during scanning. The obtained image of the boundary lattice near the crack is shown in Figure 2.

A small amount of the fcc Fe (austenite) phase was detected at the crack tip, and the substrate matrix mainly consisted of the bcc Fe (ferrite) phase. The region near the crack tip mainly included $\Sigma 3, \Sigma 5, \Sigma 7, \Sigma 9$, and $\Sigma 11$ boundaries. Some of these boundaries were analyzed to determine their misorientation angles (see positions 1 and 2 in Figure 2 containing $\Sigma 3-60^{\circ}$ and $\Sigma 5-55^{\circ}$ grain boundaries, respectively). Because the $55-60^{\circ}$ grain boundaries were part of the original austenite structure [18], the studied substrate was austenitic at high temperatures. Therefore, from the obtained EBSD images and literature data [23], the accuracy of the model proposed in this section was verified, and the $\Sigma 5$ [001] (210) $53.6^{\circ}$ fcc Fe symmetrical grain boundary model was established for the subsequent first-principles calculations.

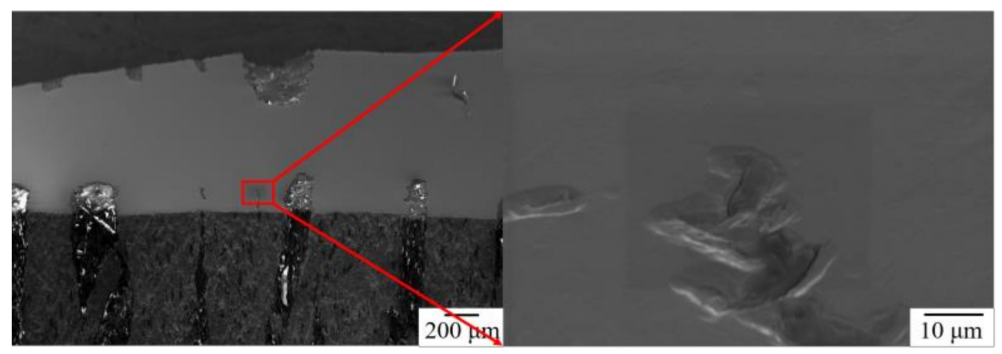

Figure 1. Analysis region of electron backscattering diffraction (EBSD). 


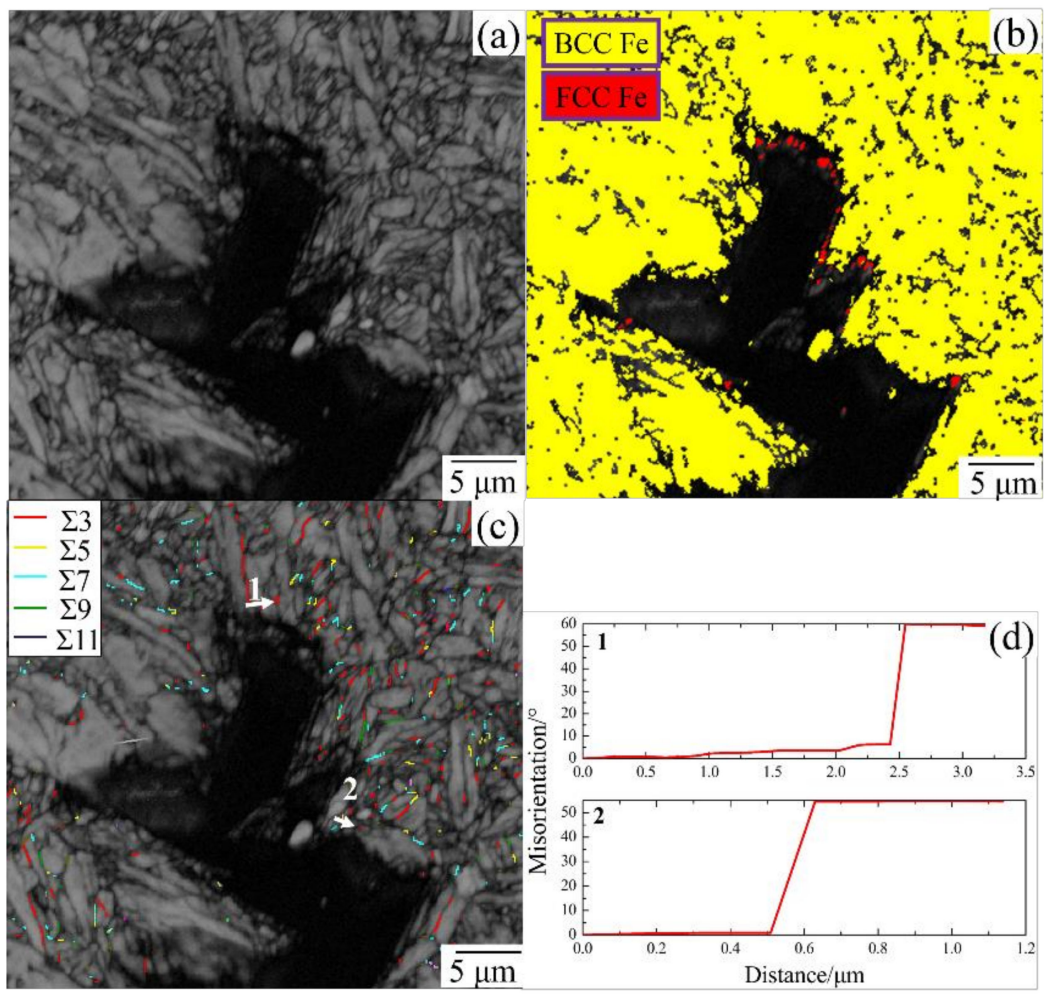

Figure 2. EBSD grain boundary analysis results: (a) morphology of grain, (b) phase proportion, (c) coincidence lattice GB, and (d) misorientation of grain boundary at positions 1 and 2 in (c).

\subsection{Calculation Method and Parameter Setting}

We performed spin-polarized first-principles calculations using the Vienna Ab-initio Simulation Package (VASP) [24-26,30,31]. The generalized gradient approximation (GGA) and PAW-PBE pseudopotential [32-35] were employed in density-functional theory simulations. The cutoff energy restricting the number of plane waves in the basis set was $500 \mathrm{eV}$. The total energy tolerance was set to $5 \times 10^{-6} \mathrm{eV} /$ atom, and the convergence criterion for geometrical optimizations was less than $0.01 \mathrm{eV} / \AA ̊$ per atom. Brillouin-zone integration was performed with the Monkhorst-Pack scheme $[36,37]$ using a uniform $3 \times 3 \times 1$ mesh. Spin polarization was considered for the bcc Fe structure because it represented a typical magnetic transitional metal.

The grain boundary model used in the calculations was established based on the results presented in Figure 3 [24]. In the $\mathrm{Zn}-\mathrm{Ni}$ co-doped grain boundary model, the Fe atoms in the intermediate layer were replaced with $\mathrm{Zn}$ or $\mathrm{Ni}$ atoms. The simulated grain boundaries are shown in Figure 4, and their corresponding codes are provided as references below. The utilized grain boundary models were subjected to complete geometric optimizations before simulations. During the grain boundary stretching, ion relaxation was performed after each simulation step. In the constructed models, each grain boundary was composed of two atoms (the middle atom was unique for a particular model, and the four atoms on the edge occupied a quarter). The $\mathrm{Ni}$ and $\mathrm{Zn}$ atoms in the $\mathrm{Zn}-\mathrm{Ni}$ co-doped grain boundary model equally accounted for $50 \%$ of the grain boundary atoms. 


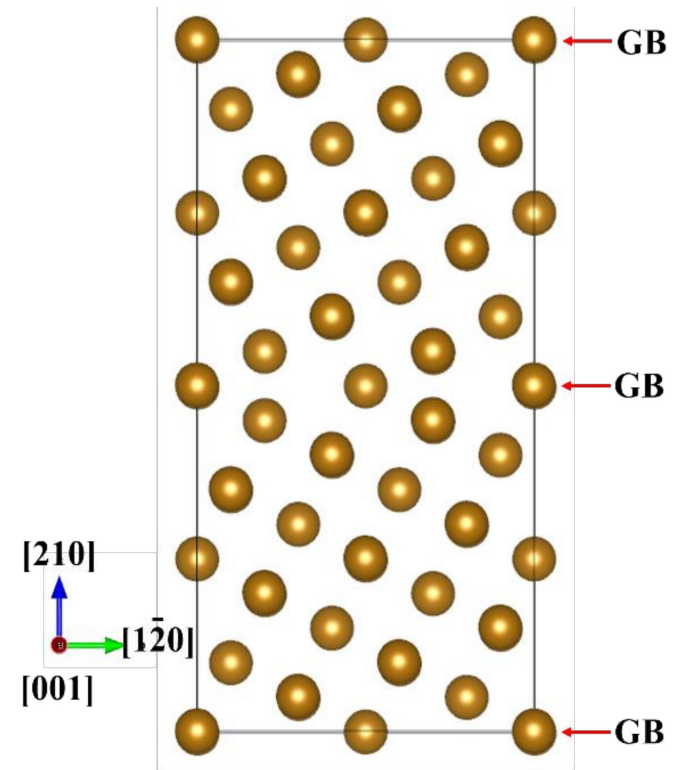

Figure 3. Fcc Fe $\Sigma 5$ [001] (210) 53.6 $6^{\circ}$ symmetric tilt grain boundary model, GB (Grain Boundary) is grain boundary surface of the GB model, a total contains two layers of GB surface, the size of initial super cell of GB model is $3.44900 \times 7.71210 \times 15.42420 \AA 3$.

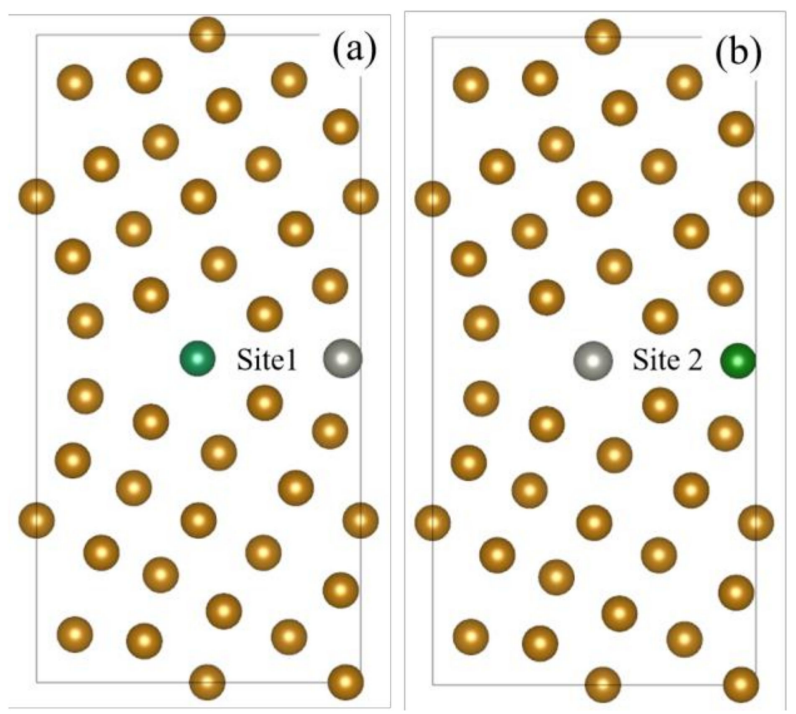

Figure 4. Grain boundary model based on the fcc Fe $\Sigma 5$ [001] (210) 53.6 symmetric tilt boundary model of Figure 3: (a) Undoped GB, (b) Zn-doped GB, and (c) Zn-Ni co-doped GB.

As shown in the Figure 5, by calculating the total free energy of the Ni atom at the center of the grain boundary (Site 1) and on the edge (Site 2) of the grain boundary model, the total free energy of the $\mathrm{Ni}$ atom in the center position model and the model on the edge are determined to be $-305.129 \mathrm{eV}$ and $-305.128 \mathrm{eV}$, respectively (Table 1 ). This indicates that the energy of the grain boundary model is lower when the $\mathrm{Ni}$ atom is in the central position, which means that the model is more stable. 


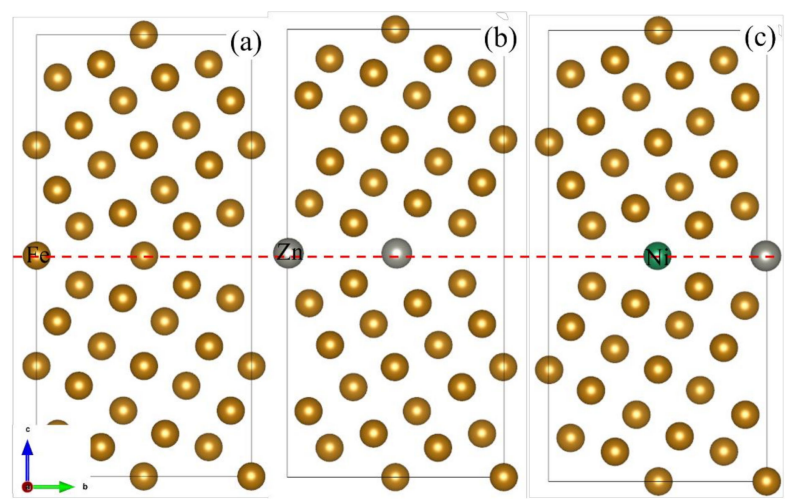

Figure 5. GB model of Ni atom at different sites: (a) The central position of the Ni atom, (b) Position of $\mathrm{Ni}$ atom on edge.

Table 1. The total free energy of grain boundaries at different sites of Ni atom.

\begin{tabular}{ccc}
\hline Site & Site 1 & Site 2 \\
\hline Total Free Energy $/ \mathrm{eV}$ & -305.129 & -305.128 \\
\hline
\end{tabular}

\subsection{Model Optimization}

First, the equilibrium lattice constant of the fcc Fe structure was optimized. The obtained magnitude was $\mathrm{a}=3.446 \AA$, and the corresponding experimental value was $\mathrm{a}=3.648 \AA$ [38]. The optimized lattice constant was subsequently used to establish suitable grain boundary models followed by the optimizations of their bulk structures, which were required due to the misalignment of boundary atoms. Figure 6 displays the changes in the interlayer spacings caused by the optimizations of the grain boundary models described in Figure $4 \mathrm{a}-\mathrm{c}$. It shows that the arrangements of atoms in the three models after the oscillations of the four interlayer spacings are very close to the bulk arrangement, indicating that the numbers of atomic layers utilized in these models were sufficient. In addition, variations of the Fe-Fe, Fe- Zn, and Fe-Ni bond lengths in the grain boundary models were observed as well (see the related discussions in the following sections). After optimizing the three grain boundary models, it was found that (a) the supercell size of the undoped Fe grain boundary model was $3.449 \times 7.712 \times 15.424 \AA^{3}$; (b) the supercell size of the $\mathrm{Zn}$-doped grain boundary model was $3.489 \times 7.670 \times 15.722 \AA^{3}$; and (c) the supercell size of the grain boundary model co-doped with zinc and nickel was $3.475 \times 7.675 \times 15.852 \AA^{3}$.

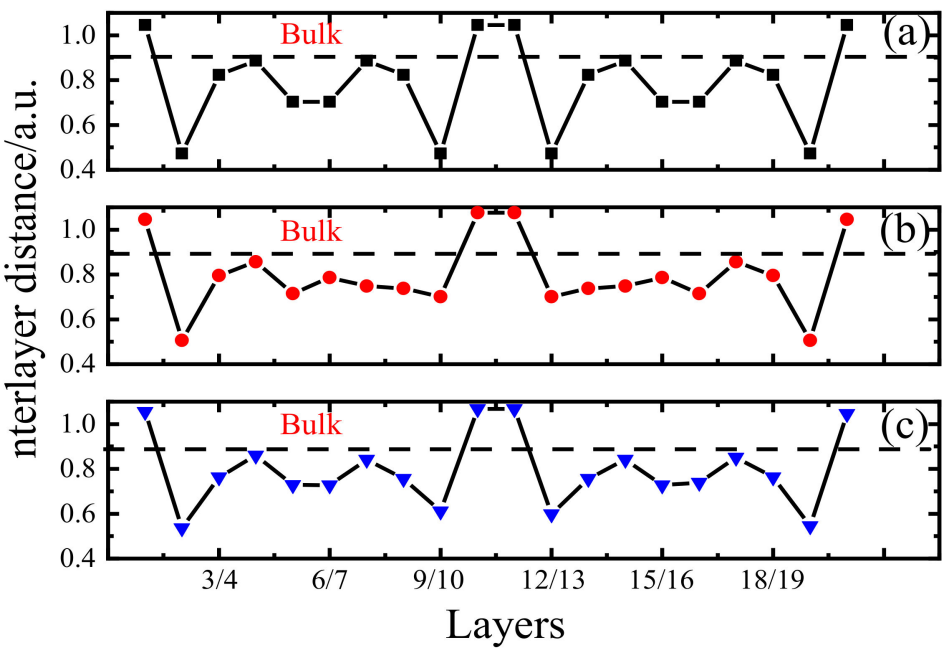

Figure 6. Interlayer spacing of grain boundary before and after doping $\mathrm{Zn}$ and Ni: (a) Undoped GB, (b) Zn-doped GB, and (c) Zn-Ni co-doped GB. 
The POSCAR file containing information on the strained structure was constructed based on the following assumptions:

1. The Poisson's ratio was ignored as suggested in previous studies [39]. In other words, the material was not deformed along the vertical strain direction (z-axis), and the unit cell parameters along the $\mathrm{x}$ and $\mathrm{y}$-directions remained unchanged.

2. The atom at the fixed twin boundary did not move. In fact, the unit cell contained two twin boundaries $(z=0(1)$ and $z=0.5)$, and only the $z=0$ (1) boundary was fixed during calculations. There were no restrictions for the movements of the two atoms with $\mathrm{z}=0.5$; however, they did not produce any displacements during the calculation process.

3. The structure with a strain of $0 \%$ was fully relaxed as the initial stable configuration. The applied strain changed the $\mathrm{c}$ value of the unit cell parameter according to the following formula:

$$
\varepsilon=\left(c_{\varepsilon}-c_{0}\right) / c_{0},
$$

where $\varepsilon$ is the magnitude of strain equal to $2 \%, 4 \%, 6 \% \ldots ; c_{\varepsilon}$ is the $c$-axis unit cell parameter of the POSCAR file corresponding to strain; and $c_{0}$ is the $c$-axis unit cell parameter at a strain of $0 \%$.

Therefore, Formula (1) can be rewritten as

$$
c_{\varepsilon}=c_{0}(1+\varepsilon) .
$$

The atomic positions, total energy, and stress of the relaxed system were directly obtained from the OUTCAR output file generated by the VASP software package, and its charge density distribution was provided in the CHGCAR file to ensure continuity of the strain path.

\section{Results and Discussion}

\subsection{Total Energy and Theoretical Tensile Strength}

The stability of a grain boundary is quantified by the total energy of its ground state. The theoretical tensile strength is a physical parameter that characterizes the mechanical properties of materials, and the total energy and theoretical tensile strength of each grain boundary in a studied system can be obtained at different tensile strains by conducting first-principles calculations.

The total energies of the undoped, $\mathrm{Zn}$-doped, and $\mathrm{Zn}-\mathrm{Ni}$ co-doped Fe grain boundaries are plotted as functions of strain in Figure 7. It shows that the increase in the tensile strain increases the total energy of each grain boundary, indicating that the utilized grain boundary models gradually become unstable under loading. When the strain of the undoped grain boundary equals $24 \%$, the energy of the system reaches a maximum, after which its magnitude decreases, and the pure Fe grain boundary remains in a relatively stable state. Because the total energy of the grain boundary of a non-fractured material gradually increases with an increase in strain, its energy entropy decreases after the fracture. Therefore, it can be concluded that the fracture of the undoped Fe grain boundary model occurs at a strain of $24 \%$. The fracture of the $\mathrm{Zn}$-doped grain boundary model is also observed after reaching a strain of $24 \%$. However, according to the corresponding plot of the total energy versus strain, the cracking of the Zn-doped grain boundary occurs earlier than the cracking of the pure Fe grain boundary. For the $\mathrm{Zn}-\mathrm{Ni}$ co-doped grain boundary model, the energy continuously increases with increasing strain, as the cracking of grain boundary occurs between undoped and Zn-doped. 


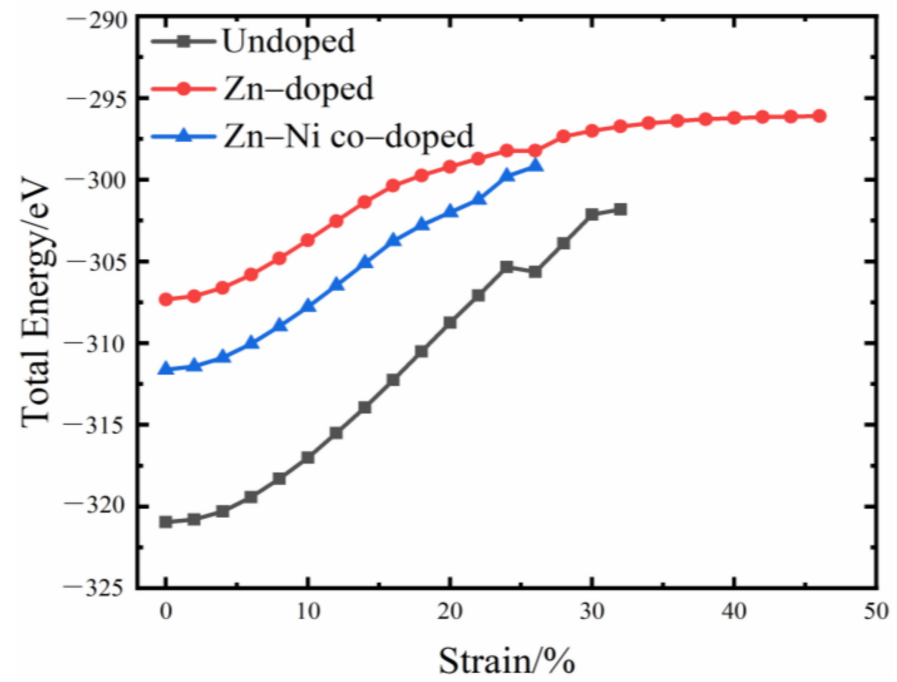

Figure 7. Relationship of total energy with strain of different GB.

In order to determine the main reasons for the grain boundary embrittlement caused by zinc doping, first-principles computational tensile tests were performed on the studied models. The first principle tensile test is to calculate the average stress acting on the system by using the first principle method and Nielsen Martin stress calculation theory [40]. Figure 8 shows the stress-strain curves obtained for the pure $\mathrm{Fe}, \mathrm{Zn}$-doped, and $\mathrm{Zn}-\mathrm{Ni}$ co-doped grain boundaries (here, a sudden drop in stress indicates that the entire grain boundary or one of its bonds is broken). When the Fe grain boundary is doped with zinc, its tensile strength and strain rate are significantly reduced. The pure Fe grain boundary breaks after stretching to $22 \%$, and its tensile strength is equal to approximately $25.04 \mathrm{GPa}$. The Zn-doped grain boundary fractures after stretching to $14 \%$, and its tensile strength is approximately $16.37 \mathrm{Gpa}$. Meanwhile, replacing $\mathrm{Zn}$ atoms with $\mathrm{Ni}$ in the $\mathrm{Zn}$-doped grain boundary model increases both its tensile strength and strain rate. As a result, the $\mathrm{Zn}-\mathrm{Ni}$ co-doped grain boundary fractures after stretching to $16 \%$, and its tensile strength is equal to approximately $19.12 \mathrm{Gpa}$. However, these values are still lower than the tensile strength and strain rate of the undoped Fe grain boundary. Therefore, introducing Ni atoms into the $\mathrm{Zn}$-doped Fe structure provides a basis for the suppression of its liquid zinc-induced embrittlement.

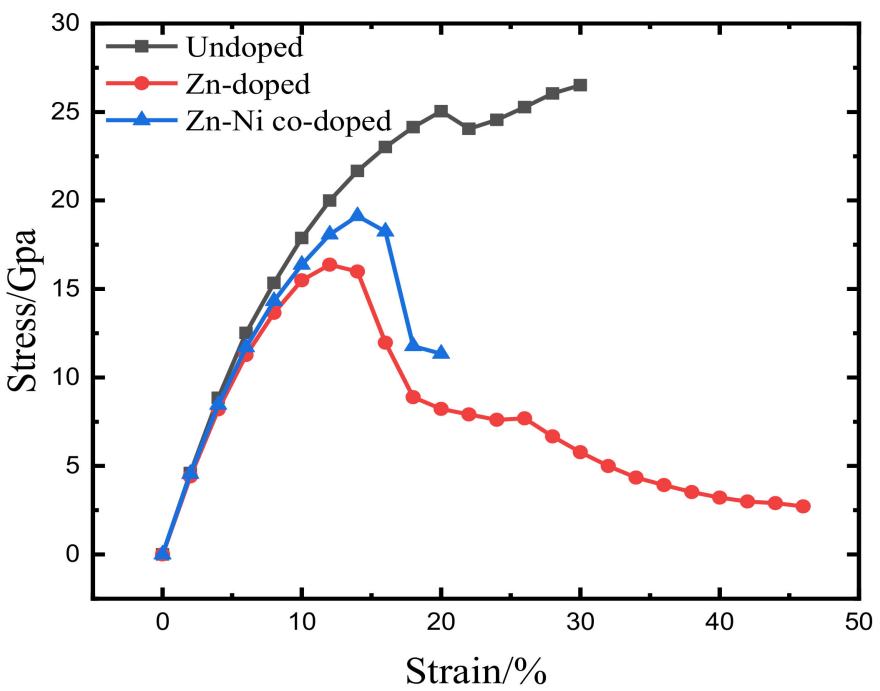

Figure 8. Stress-strain curve calculated by first-principles. 


\subsection{Chemical Bond Structure}

To determine the fracture points of the studied grain boundaries, their specific fractures that occurred during the stretching process are shown in Figure 9. For the pure Fe grain boundary, the interlayer spacing between the several atomic layers located near the boundary changes significantly during stretching, and the symmetrical tilt characteristics of this model after stretching are no longer observed. This indicates that the strength of Fe-Fe bonds in the undoped Fe grain boundary model is relatively high, and that this boundary is not prone to fracture. At strains between $0 \%$ and $12 \%$, the atomic configuration of the $\mathrm{Zn}$-doped grain boundary is close to that of the undoped boundary. When the $\mathrm{Zn}$-doped grain boundary is stretched to $12 \%$, its structure breaks due to the cleavage of Fe-Zn bonds. The atomic configuration of the $\mathrm{Zn}-\mathrm{Ni}$ co-doped grain boundary at strains between $0 \%$ and $14 \%$ is also very close to those of the undoped and $\mathrm{Zn}$-doped grain boundaries. However, the former boundary breaks after stretching to $16 \%$, owing to the cleavages of Fe-Zn or Ni-Fe bonds.

(a)

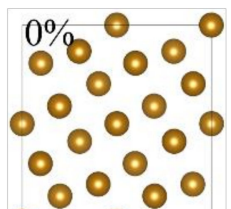

(b)
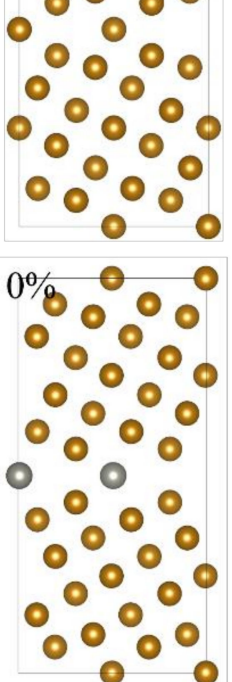

(c)
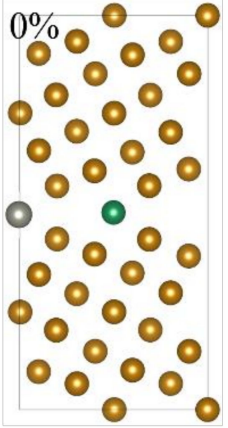

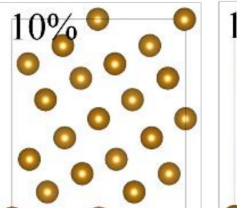

$\odot$

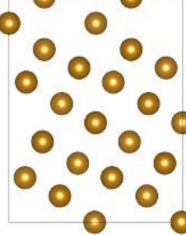

$10 \%$
0
0

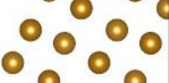

10

$0_{0}^{0} 0^{\circ}$

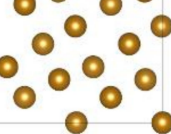

$10 \% \%$

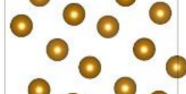

$0_{0}^{0} 0_{0}^{0}$

-

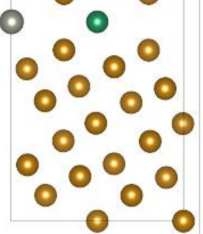

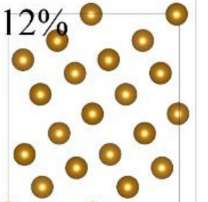

- 0

$0_{0}^{0} 0$

$0_{0}^{0} 0$

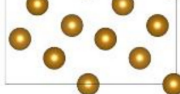

$12 \% \circ \div$

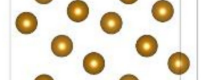

$0_{0}^{0} 0$

- 0

$0_{0}^{0} 0$

$0^{0} 0^{0}$

$0_{0}^{0}$

$12 \% 00$

$0_{0}^{0} 0$

$0_{0}^{0} 0$

$0^{\circ} 0^{\circ}$

$0^{0} 0^{0}$

$0_{0}^{0} 0_{0}^{0}$

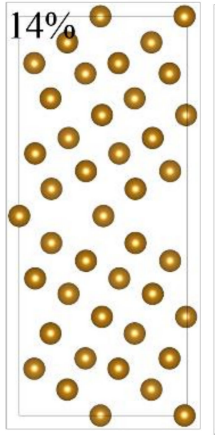

$20 \%$

$0^{\circ} 0$

$0^{0} 0^{0}$

$0^{\circ}$

0 0 0

$\begin{array}{cc}0 & 0 \\ 0 & 0 \\ 0 & 0\end{array}$

$0_{0}^{0} 0_{0}^{0}$

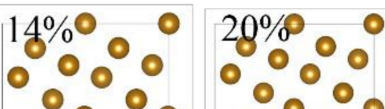

0.0.0

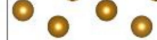

- 0

$0_{0}^{0} 0_{0}^{0}$

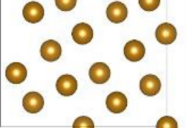

0.0

००००

- $\bigcirc$

0.00

$0^{0} 0$

$0_{0}^{0} 0_{0}^{0}$

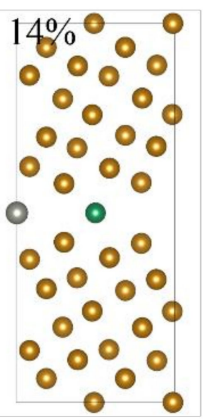

Figure 9. Grain boundaries under different strains: (a) Undoped GB, (b) Zn-doped GB, and (c) Zn-Ni co-doped GB.

To explore the specific fractures of the three grain boundary models, their Fe-Fe, Fe-Zn, and Ni-Fe bonds were examined in detail. Figure 10 shows the chemical structures of these bonds at a zero strain (it also contains the locations of the corresponding atoms and specific $\mathrm{Fe}-\mathrm{Fe}, \mathrm{Fe}-\mathrm{Zn}$, and Ni-Fe bond lengths). The brown balls in the model represent Fe atoms; the gray balls denote $\mathrm{Zn}$ atoms; and the green balls represent $\mathrm{Ni}$ atoms. 


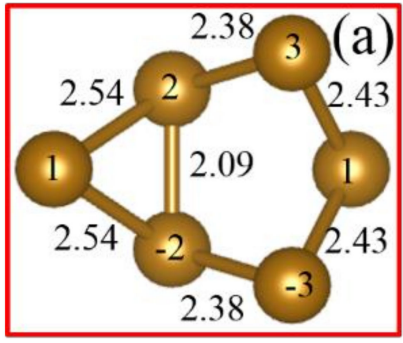

Fe
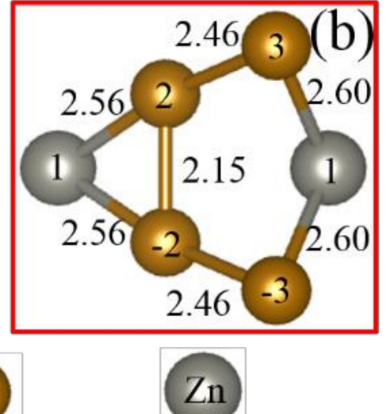

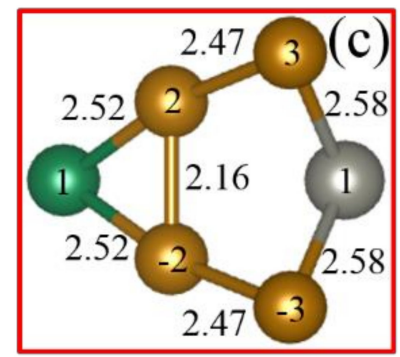

$\mathrm{Ni}$

Figure 10. Chemical bond structures of Fe-Fe, Fe- Zn and Ni-Fe bonds in different $\mathrm{GB}$ models: (a) Undoped GB, (b) Zn-doped GB, and (c) Zn-Ni co-doped GB, unit: A.

According to Figure 10, the main bonds affecting the strength of the pure Fe grain boundary are the $\mathrm{Fe}(2)-\mathrm{Fe}(-2), \mathrm{Fe}(1)-\mathrm{Fe}(3)$, and $\mathrm{Fe}(1)-\mathrm{Fe}(2)$ bonds; the main bonds affecting the strength of the $\mathrm{Zn}$-doped grain boundary are the $\mathrm{Fe}(2)-\mathrm{Fe}(-2), \mathrm{Zn}(1)-\mathrm{Fe}(3)$, and $\mathrm{Zn}(1)-$ $\mathrm{Fe}(2)$ bonds; and the main bonds affecting the strength of the $\mathrm{Zn}-\mathrm{Ni}$ co-doped grain boundary are the $\mathrm{Fe}(2)-\mathrm{Fe}(-2), \mathrm{Zn}(1)-\mathrm{Fe}(3)$, and $\mathrm{Ni}(1)-\mathrm{Fe}(2)$ bonds. Among these three types of bonds, the $\mathrm{Fe}(2)-\mathrm{Fe}(-2)$ bond parallel to the stretching direction has the greatest influence on the grain boundary strength followed by the $\mathrm{Fe}(1)-\mathrm{Fe}(3)$ and $\mathrm{Zn}(1)-\mathrm{Fe}(3)$ (oriented at an angle of approximately $30^{\circ}$ with respect to the stretching direction) and the $\mathrm{Fe}(1)-\mathrm{Fe}(2)$, $\mathrm{Zn}(1)-\mathrm{Fe}(2)$, and $\mathrm{Ni}(1)-\mathrm{Fe}(2)$ bonds (oriented at an angle of approximately $60^{\circ}$ with respect to the stretching direction). Figure 10 also shows that the lengths of the three types of bonds in the $\mathrm{Zn}$-doped grain boundary exceed those in the undoped grain boundary model by $0.06 \AA, 0.17 \AA$, and $0.02 \AA$, respectively. Among them, the greatest increase was observed for the $\mathrm{Zn}(1)-\mathrm{Fe}(3)$ bond. The lengths of the $\mathrm{Fe}(2)-\mathrm{Fe}(3)$ bonds located in the second and third layers also increased by $0.08 \AA$. The atomic radius of Fe is $1.24 \AA$, the atomic radius of $\mathrm{Zn}$ is $1.33 \AA$, and the atomic radius of $\mathrm{Zn}$ is slightly larger than that of Fe; therefore, $\mathrm{Zn}$ doping at the grain boundary causes its expansion accompanied by the increase in the bond length. Because the bond length is closely related to the bond strength, the increase in the bond length caused by the grain boundary expansion reduces the grain boundary strength In particular, the largest increase is observed for the $\mathrm{Fe}(1)-\mathrm{Fe}(3)$ bond length, indicating that the strength of the grain boundary is significantly reduced. This type of grain boundary expansion caused by the atomic size mismatch and weakening of grain boundary bonding is one of the reasons for the observed grain boundary embrittlement. Compared with the $\mathrm{Zn}$-doped grain boundary model, the corresponding bond lengths in the $\mathrm{Zn}-\mathrm{Ni}$ co-doped grain boundary model increased by $0.01 \AA$, decreased by $0.04 \AA$, and decreased by $0.02 \AA$, respectively. This shows that after $\mathrm{Ni}$ atoms partially replace $\mathrm{Zn}$ atoms, the $\mathrm{Fe}(2)-\mathrm{Fe}(-2)$ bond expands, while the $\mathrm{Ni}(1)-\mathrm{Fe}(2)$ and $\mathrm{Zn}(1)-\mathrm{Fe}(3)$ bonds contract.

According to Figure $11 \mathrm{a}-\mathrm{c}$, the increase in the bond length caused by grain boundary expansion always occurs during the stretching process. In Figure 11a, the $\mathrm{Fe}(2)-\mathrm{Fe}(-2)$ bond length of the Zn-doped grain boundary is larger than those of the pure Fe and $\mathrm{Zn}-\mathrm{Ni}$ co-doped grain boundaries. In Figure 11b,c, the same trends are observed for the changes in the bond lengths of the $\mathrm{Zn}$-doped and $\mathrm{Zn}-\mathrm{Ni}$ co-doped grain boundary models. After stretching to $10 \%$, the lengths of the $\mathrm{Fe}(2)-\mathrm{Fe}(-2), \mathrm{Zn}(1)-\mathrm{Fe}(3)$, and $\mathrm{Zn}(1)-\mathrm{Fe}(2)$ bonds at the $\mathrm{Zn}$-doped grain boundary suddenly increase due to their cleavages. 

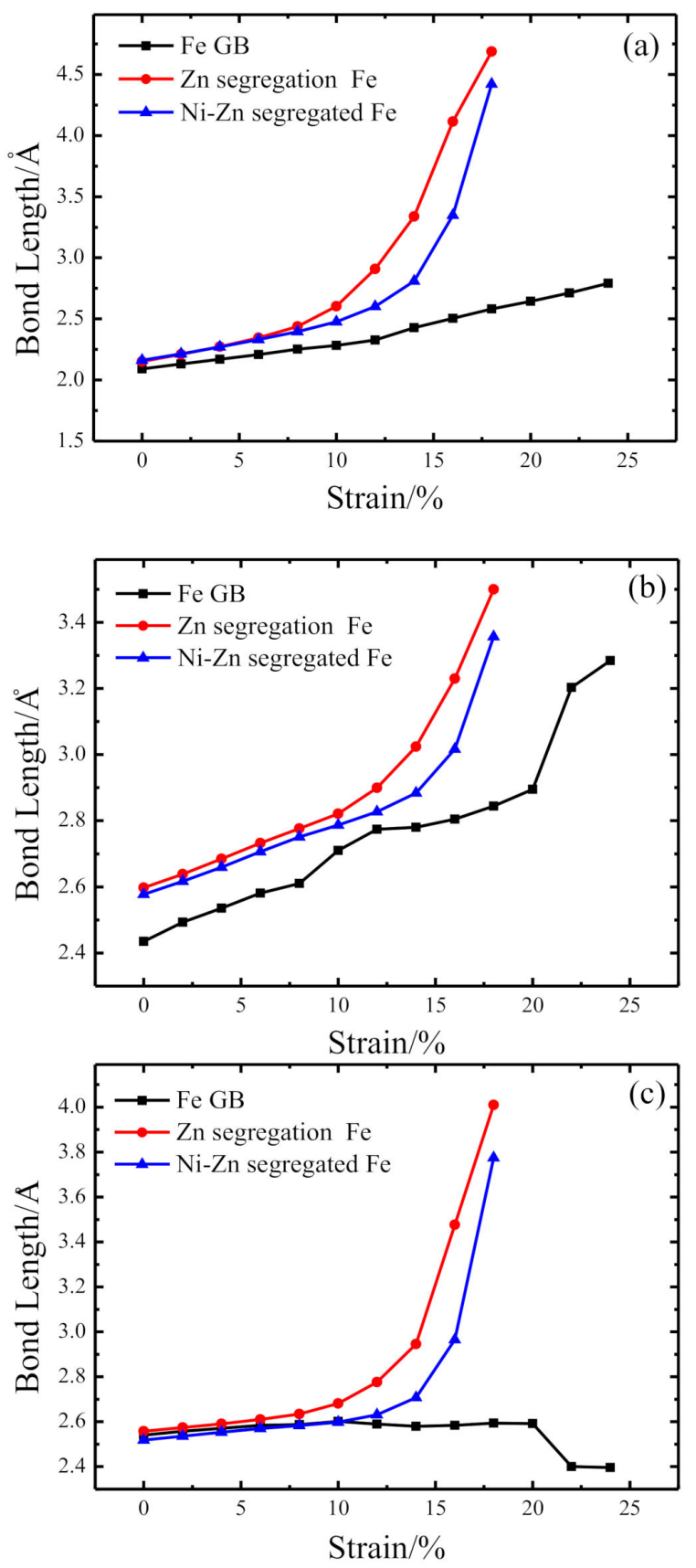

Figure 11. Variation of bond length of $\mathrm{Fe}-\mathrm{Fe}, \mathrm{Fe}-\mathrm{Zn}$ and Ni-Fe bonds in the GB model at different strain: (a) Fe(2)-Fe(-2) bond of undoped GB, Zn-doped GB, and Zn-Ni co-doped GB, (b) Fe(1)-Fe(3) bond of undoped GB, Zn(1)-Fe(3) bond of Zn-doped GB and Zn-Ni co-doped GB, (c) Fe(1)-Fe(2) bond of undoped GB, Zn(1)-Fe(2) bond of Zn-doped GB, Ni(1)-Fe(2) bond Zn-Ni co-doped GB.

\subsection{Electronic Structure}

Figure 12 compares the charge density distributions of the $\mathrm{Fe}(2)-\mathrm{Fe}(-2)$ bonds located on the (002) plane that were obtained for the undoped, Zn-doped, and Zn-Ni co-doped grain boundaries. It shows that at a strain of $0 \%$, the charge density of the $\mathrm{Fe}(2)-\mathrm{Fe}(-2)$ bonds in the $\mathrm{Zn}$-doped grain boundary model is lower than those of the $\mathrm{Fe}(2)-\mathrm{Fe}(-2)$ bonds in the other two models, indicating that the strength of these bonds decreases after zinc doping. After replacing $\mathrm{Zn}$ atoms with $\mathrm{Ni}$ atoms, the charge density of the $\mathrm{Fe}(2)-\mathrm{Fe}(-2)$ bonds at the $\mathrm{Zn}-\mathrm{Ni}$ co-doped grain boundary increases, owing to the increase in the $\mathrm{Fe}(2)-\mathrm{Fe}(-2)$ bond strength. 
(a)

(b)
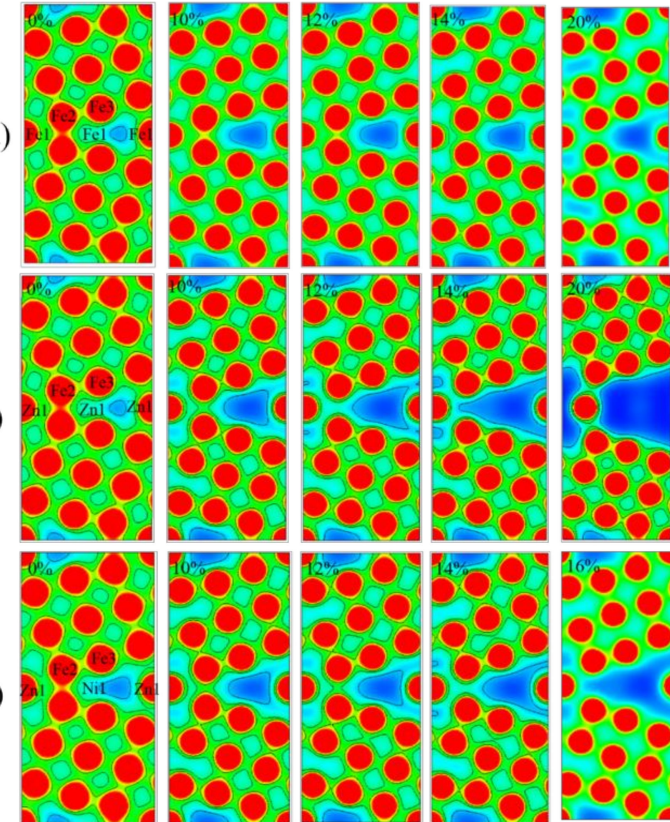

Figure 12. Charge distribution of $\mathrm{Fe}(2)-\mathrm{Fe}(-2)$ bond on (002) plane under different strains: (a) Undoped GB, (b) Zn-doped GB, and (c) Zn-Ni co-doped GB.

When the models are stretched to $12 \%$, the charge density of the $\mathrm{Fe}(2)-\mathrm{Fe}(-2)$ bonds in the $\mathrm{Zn}$-doped grain boundary model becomes much lower than those in the pure $\mathrm{Fe}$ and $\mathrm{Zn}-\mathrm{Ni}$ co-doped models; however, it does not reach zero. Therefore, according to the obtained tensile curves, both boundaries exhibit the same tensile strengths. When the tensile strain reaches $14 \%$, a slight difference is observed between the tensile strengths of the two models, which corresponds to the tiny blue area in Figure $12 \mathrm{~b} 14 \%$ (the charge density in this area ranges from 0 to 0.02 electrons $/ \mathrm{Bohr}^{3}$, which is very close to zero). When the tensile strain increases to $20 \%$, the tensile strength of the $\mathrm{Fe}(2)-\mathrm{Fe}(-2)$ bond in the $\mathrm{Zn}$-doped grain boundary model becomes significantly lower than the values obtained for the undoped and Zn-Ni co-doped grain boundary models (see Figure 12b 20\%). Here, the charge density of the $\mathrm{Fe}(2)-\mathrm{Fe}(-2)$ bond basically approaches zero (indicating that this bond is almost broken), while the same bonds in Figure 12a,c 20\% still retain high charge densities. When the $\mathrm{Zn}$-doped grain boundary is stretched to $14 \%$, it fractures; as a result, the blue area expands to a maximum value, and the charge density becomes zero.

Figures 13-15 compare the charge densities of the $\mathrm{Fe}(1)-\mathrm{Fe}(2)$ and $\mathrm{Fe}(1)-\mathrm{Fe}(3)$ bonds, $\mathrm{Zn}(1)-\mathrm{Fe}(2)$ and $\mathrm{Zn}(1)-\mathrm{Fe}(3)$ bonds, and $\mathrm{Ni}(1)-\mathrm{Fe}(2)$ and $\mathrm{Ni}(1)-\mathrm{Fe}(3)$ bonds, which were obtained for the three different models stretched to $0 \%$. The numbers of atomic layers and $\mathrm{Fe}, \mathrm{Zn}$, and $\mathrm{Ni}$ atoms at the grain boundaries are marked in these figures accordingly. The charge density of the Fe-Ni bonds is lower than that of the Fe-Fe bonds and is slightly higher than the charge density of the Fe-Zn bonds, indicating that the strength of Fe-Ni bonds is lower than that of the Fe-Fe bonds and higher than the strength of the Fe-Zn bonds. The valence electron structures of $\mathrm{Fe}, \mathrm{Zn}$, and Ni atoms are $3 \mathrm{~d}^{6} 4 \mathrm{~s}^{2}, 3 \mathrm{~d}^{10} 4 \mathrm{~s}^{2}$, and $3 \mathrm{~d}^{8} 4 \mathrm{~s}^{2}$, respectively. Although $\mathrm{Zn}$ has a larger number of valence electrons than $\mathrm{Fe}$ and $\mathrm{Ni}$ atoms, its $3 \mathrm{~d}$ orbital is full and, therefore, does not participate in the bonding process (in fact, only the two electrons of the $\mathrm{Zn} 4 \mathrm{~s}$ orbital form bonds with other atoms). Hence, the Fe- $\mathrm{Zn}$ bond is weaker than the Fe-Ni and Fe-Fe bonds, and the latter determine the boundary strength. The charge density of the $\mathrm{Fe}(2)-\mathrm{Fe}(-2)$ bonds at the $\mathrm{Zn}$-doped grain boundary is lower than those of the same bonds at the pure Fe and $\mathrm{Zn}-\mathrm{Ni}$ co-doped boundaries, which will be explained in more detail below. 


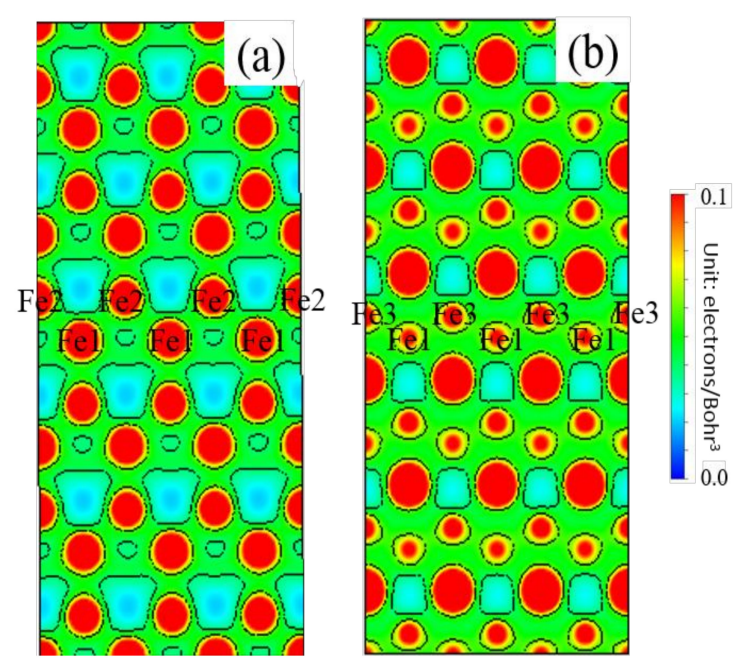

Figure 13. Charge distribution of (a) $\mathrm{Fe}(1)-\mathrm{Fe}(2)$ bond and (b) $\mathrm{Fe}(1)-\mathrm{Fe}(3)$ bond on (002) plane of undoped GB at $0 \%$ stain.

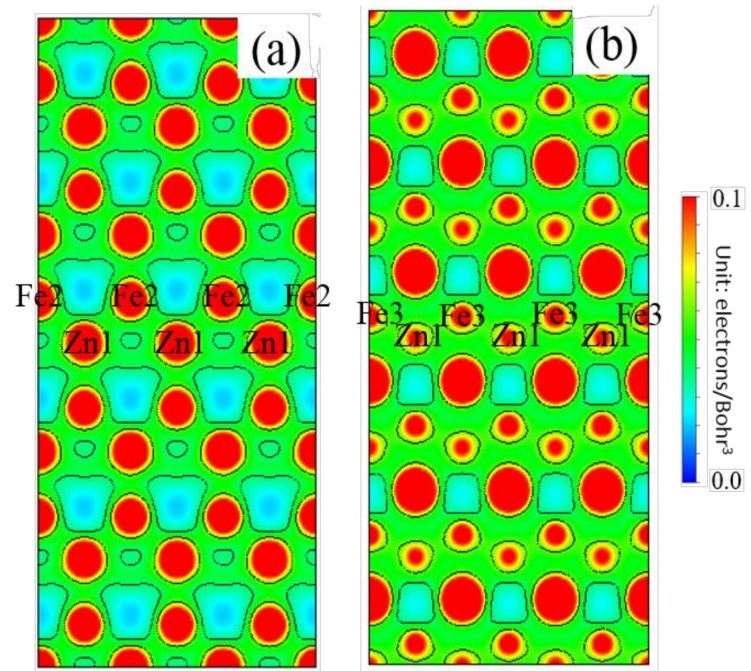

Figure 14. Charge distribution of (a) $\mathrm{Zn}(1)-\mathrm{Fe}(2)$ bond and (b) $\mathrm{Zn}(1)-\mathrm{Fe}(3)$ bond on (002) plane of Zn-doped GB at $0 \%$ stain.
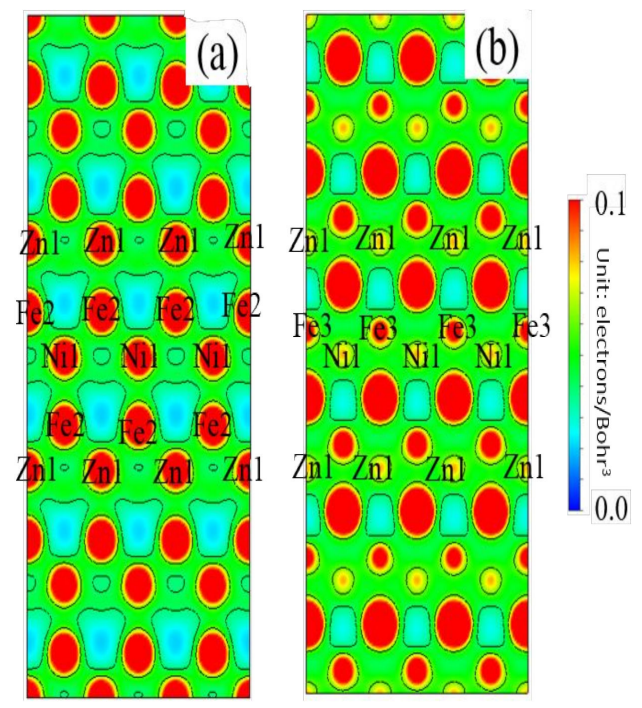

Figure 15. Charge distribution of (a) $\mathrm{Ni}(1)-\mathrm{Fe}(2)$ bond and (b) $\mathrm{Ni}(1)-\mathrm{Fe}(3)$ bond on (002) plane of Zn-Ni co-doped GB at $0 \%$ stain. 


\subsection{Density of States}

Figure 16 shows the partial wave densities of states of the $\mathrm{Fe}(2)$ atoms in the undoped, $\mathrm{Zn}$-doped, and $\mathrm{Zn}-\mathrm{Ni}$ co-doped Fe grain boundary models stretched to $0 \%$. In the energy region between $-4.0 \mathrm{eV}$ and $1.5 \mathrm{eV}$, the density of states obtained for the $\mathrm{d}$ electrons of the $\mathrm{Fe}(2)$ atoms in the Zn-doped grain boundary model is higher than that of the d electrons of the $\mathrm{Fe}(2)$ atoms in the pure Fe grain boundary model. Hence, the $\mathrm{d}$ electrons located between the $\mathrm{Fe}(2)$ and $\mathrm{Zn}(1)$ atoms at the $\mathrm{Zn}$-doped grain boundary exhibit a hybrid resonance, which increases the density of states, indicating that the chemical bonds formed between these atoms are covalent bonds. One the one hand, the d electrons of the $\mathrm{Fe}(2)$ atoms at the Zn-doped grain boundary are more localized than the delectrons of the $\mathrm{Fe}(2)$ atoms in the undoped Fe grain boundary model. On the other hand, the d electrons of the $\mathrm{Fe}(2)$ and $\mathrm{Zn}(1)$ atoms in the $\mathrm{Zn}$-doped grain boundary model produce hybrid peaks at an energy of approximately $-7 \mathrm{eV}$. Because the electron localization and electron hybridization processes are characteristic of covalent bonds, the produced Fe-Zn bonds represent not typical metal bonds, but covalent bonds with covalent properties. However, Ni doping considerably decreases the degree of electronic localization of Fe atoms. In order to describe the nature of Fe-Zn covalent bonding in more detail, a differential charge density map constructed for the $\mathrm{Fe}(1), \mathrm{Zn}(1)$, and $\mathrm{Ni}(1)$ atoms on the (002) planes of the studied grain boundaries is investigated in the next section.
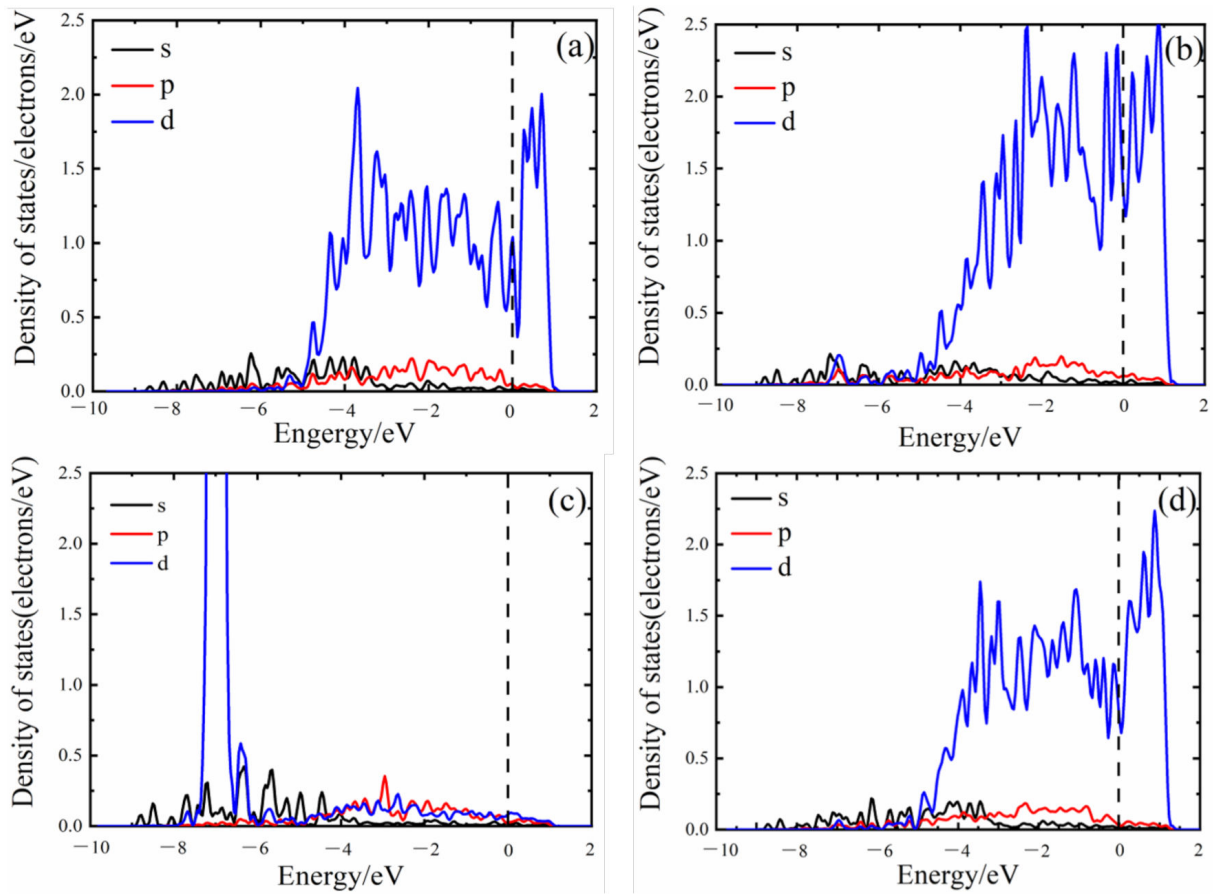

Figure 16. Partial Density of States: (a) Fe(2) atom in undoped GB, (b) and (c) Fe(2) and Zn(1) atom in Zn-doped GB, and (d) Fe(2) atom in Zn-Ni co-doped GB.

\subsection{Differential Charge Density}

The differential charge density map is obtained by subtracting bond charge densities from atomic charge densities at the corresponding points. By calculating and analyzing the resulting differential charge densities, it is possible to determine the charge transfer parameters and polarization direction of a particular bond during the bonding and electron coupling processes. In this work, the differential charge density was calculated by the following formula [41]:

$$
\Delta \rho=\rho_{A B}-\rho_{A}-\rho_{\mathrm{B}},
$$

where $\rho_{\mathrm{AB}}$ represents the total charge density after optimizing the $A B$ structure, while $\rho_{\mathrm{A}}$ and $\rho_{\mathrm{B}}$ are the charge densities of structures $A$ and $B$, respectively. The last two parameters 
were subtracted to obtain the charge density changes of $A$ and $B$ after bonding and analyze the charge movements that occurred during this process.

Figure 17 shows the differential charge densities on the (002) plane determined for the $\mathrm{Fe}(1)$ atoms at the pure $\mathrm{Fe}$ grain boundary, $\mathrm{Zn}(1)$ atoms at the $\mathrm{Zn}$-doped grain boundary, and $\mathrm{Ni}(1)$ and $\mathrm{Zn}(1)$ atoms at the $\mathrm{Zn}-\mathrm{Ni}$ co-doped grain boundary. The charge accumulations around $\mathrm{Fe}$ and $\mathrm{Ni}$ atoms are denoted by almost the same colors, indicating the absence of directionality and the metallic nature of their bonds. In contrast, the charges accumulated around $\mathrm{Zn}$ atoms are directional (the right yellow charges differ in energy from the upper and lower yellow charges, suggesting the formation of covalent bonds). After Ni addition, the directionality of the accumulated charges around $\mathrm{Zn}$ atoms is improved, and the upper, lower, and right yellow charges have almost the same energies. The Fe(1) atoms at the pure Fe grain boundary form metallic bonds with other Fe atoms, leading to charge accumulation. Because metallic bonds are not directional, the accumulated charge is relatively large. The $\mathrm{Zn}(1)$ atoms at the $\mathrm{Zn}$-doped grain boundary also form bonds with Fe atoms; however, because these bonds are covalent (and, therefore, directional), the accumulated charge around $\mathrm{Zn}$ atoms is relatively small. Finally, the Ni(1) atoms at the $\mathrm{Zn}-\mathrm{Ni}$ co-doped grain boundary form metallic bonds with Fe atoms, resulting in the charge accumulation around the latter. Because metallic bonds have no directionality, the accumulated charge is relatively large. However, in the same grain boundary model, charge accumulation also occurs between the $\mathrm{Fe}(2)$ and $\mathrm{Fe}(-2)$ atoms in the $\mathrm{Zn}$-doped areas, and the charge density around $\mathrm{Ni}(1)$ atoms is higher than that before the doping. From these results, it can be concluded that the charge accumulated between $\mathrm{Fe}(2)$ and $\mathrm{Fe}(-2)$ atoms has been transferred to the vicinities of $\mathrm{Ni}(1)$ atoms.
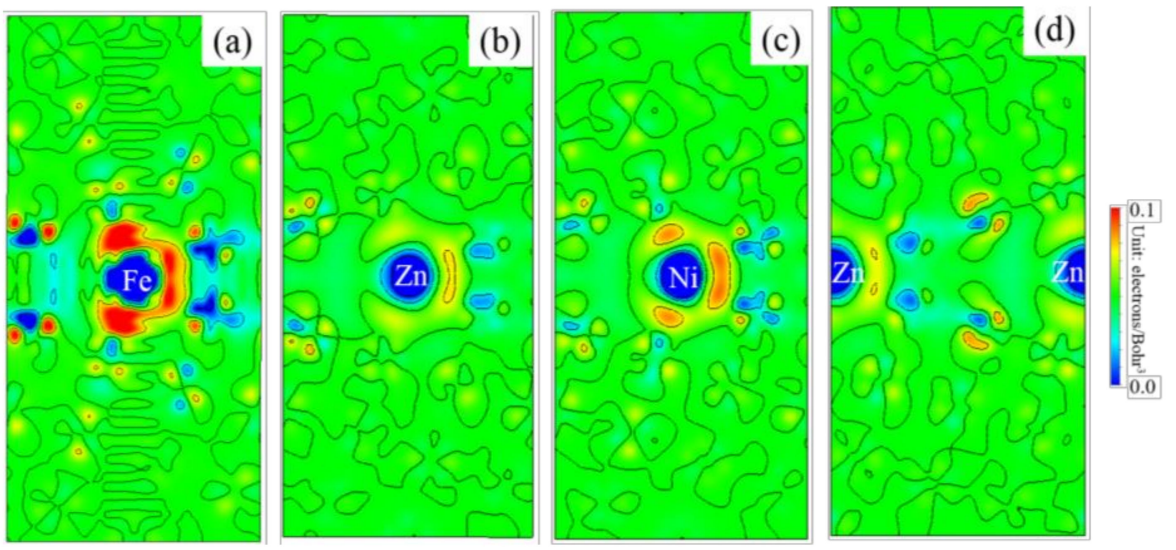

Figure 17. (a) Differential charge of Fe(1) atom on (100) plane of undoped GB, (b) Differential charge of $\mathrm{Zn}(1)$ atom on (100) plane of Zn-doped GB, (c) Differential charge of $\mathrm{Ni}(1)$ atom on (100) plane of Zn-Ni co-doped GB, and (d) Differential charge of Zn(1) atom on (100) plane of Zn-Ni co-doped GB.

In general, after the zinc doping of the Fe grain boundary, its mechanical properties deteriorate, leading to premature cracking. This phenomenon is caused by the grain boundary expansion accompanied by the weakening of $\mathrm{Fe}(2)-\mathrm{Fe}(-2)$ bonds, which in turn embrittles the boundary. When $\mathrm{Ni}$ atoms replace $\mathrm{Zn}$ atoms in the $\mathrm{Zn}$-doped Fe grain boundary, its mechanical properties improve, and the cracking process is suppressed because Ni-Fe metallic bonds are stronger than Fe-Zn covalent bonds.

\section{Conclusions}

After the $\mathrm{Zn}$-Ni co-doping of the Fe grain boundary, Ni atoms form metallic bonds with Fe atoms, thus increasing both the charge density of Fe-Fe bonds (as compared with that of the Fe-Fe bonds at the $\mathrm{Zn}$-doped grain boundary). The produced Fe-Ni bonds are stronger than Fe-Zn bonds, suggesting that Ni addition can inhibit the fracture of the fcc Fe grain boundary. 
In this study, the main reasons for the liquid zinc-induced embrittlement and its subsequent suppression process are identified, and first-principles calculations are performed to determine the influences of $\mathrm{Zn}$ doping and $\mathrm{Zn}-\mathrm{Ni}$ co-doping on the properties of the $\Sigma 5$ [001] (210) $53.6^{\circ}$ fcc Fe grain boundary. From the obtained results, the following conclusions have been drawn:

1. EBSD was used to establish an appropriate grain boundary model to further explain the brittle fracture induced by liquid zinc.

2. Because the sizes of $\mathrm{Zn}$ and Fe atoms are not the same, doping the pure Fe grain boundary leads to its expansion, which increases the lengths of Fe-Fe bonds, leading to their weakening, and reduces the overall boundary strength.

3. The Zn doping of the grain boundary results in the formation of $\mathrm{Zn}$-Fe covalent bonds, which decrease the charge density of Fe-Fe bonds and weakens them. Meanwhile, the Fe- $\mathrm{Zn}$ bonds are oriented at a certain angle with respect to the grain boundary direction and possess very low strengths. After the weakened Fe-Fe bonds are broken, the strength of the grain boundary drops significantly.

4. After the $\mathrm{Zn}-\mathrm{Ni}$ co-doping of the grain boundary, Ni atoms form metallic bonds with Fe atoms, which increase the charge density and strength of Fe-Fe bonds with respect to that of the Fe-Fe bonds in the Zn-doped grain boundary.

5. The Fe-Ni bonds at the $\mathrm{Zn}-\mathrm{Ni}$ co-doped grain boundary are stronger than the Fe- $\mathrm{Zn}$ bonds and, therefore, can potentially suppress the fcc Fe grain boundary fracture.

Author Contributions: C.D.: Writing-original draft. W.P.: Investigation. Z.M.: Formal analysis. Y.Z.: Funding acquisition, Methodology. H.T.: Resources. G.W.: Funding acquisition, Methodology, Project administration, Supervision, Writing-review \& editing. All authors have read and agreed to the published version of the manuscript.

Funding: This research was funded by National Natural Science Foundation of China (Grant Nos. 51771226); Science and Technology Committee of Shanghai (Grant No. 21ZR1423600) and Central Government Guides the Development of Local Science and Technology Special Fund of China (Grant No. 216Z1004G).

Data Availability Statement: Data presented in this article is available on request from the corresponding author.

Acknowledgments: The author Zhao would like to thank the support from National Natural Science Foundation of China (Grant Nos. 51771226) and author Wu would like to thank the support from the Science and Technology Committee of Shanghai (Grant No. 21ZR1423600) and Central Government Guides the Development of Local Science and Technology Special Fund of China (Grant No. 216Z1004G).

Conflicts of Interest: The authors declared that they have no conflict of interest to this work. We declare that we do not have any commercial or associative interests that represent a conflict of interest in connection with the work submitted.

\section{References}

1. Drillet, P.; Grigorieva, R.; Leuillier, G.; Vietoris, T. Study of cracks propagation inside the steel on press hardened steel zinc based coatings. La Metall. Ital. 2012. [CrossRef]

2. Kondratiuk, J.; Kuhn, P.; Labrenz, E.; Bischoff, C. Zinc coatings for hot sheet metal forming: Comparison of phase evolution and microstructure during heat treatment. Surf. Coat. Technol. 2011, 205, 4141-4153. [CrossRef]

3. Lee, C.W.; Choi, W.S.; Cho, L.; Cho, Y.R.; De Cooman, B.C. Liquid-metal-induced embrittlement related microcrack propagation on Zn-coated press hardening steel. ISIJ Int. 2015, 55, 264-271. [CrossRef]

4. Lee, C.W.; Fan, D.W.; Sohn, I.R.; Lee, S.J.; De Cooman, B.C. Liquid-metal-induced embrittlement of Zn-coated hot stamping steel. Metall. Mater. Trans. A 2012, 43, 5122-5127. [CrossRef]

5. Peng, H.; Peng, W.; Lu, R.; Wu, G.; Zhang, J. Diffusion and cracking behavior involved in hot press forming of Zn coated 22MnB5. J. Alloys Compd. 2019, 806, 195-205. [CrossRef]

6. Chang, J.K.; Lin, C.S.; Wang, W.R.; Cheng, W.J. Microstructural evaluation and property change of 5 wt pct Al-Zn coating on press hardening steel during austenitization. Metall. Mater. Trans. A 2018, 49, 3715-3728. [CrossRef] 
7. Chang, J.K.; Lin, C.S. Microstructural Evolution of 11Al-3Mg-Zn Ternary Alloy-Coated Steels During Austenitization Heat Treatment. Metall. Mater. Trans. A Phys. Metall. Mater. Sci. 2017, 48, 3734-3744. [CrossRef]

8. Schino, A. Di Manufacturing and Applications of Stainless Steels. Metals 2020, 10, 327. [CrossRef]

9. Bauer, K.D.; Todorova, M.; Hingerl, K.; Neugebauer, J. A first principles investigation of zinc induced embrittlement at grain boundaries in bcc iron. Acta Mater. 2015, 90, 69-76. [CrossRef]

10. Miyazawa, N.; Hakamada, M.; Mabuchi, M. Atomic bond-breaking behaviour during grain boundary fracture in a C-segregated Fe grain boundary. Philos. Mag. Lett. 2017, 97, 311-319. [CrossRef]

11. Lu, G.H.; Deng, S.; Wang, T.; Kohyama, M.; Yamamoto, R. Theoretical tensile strength of an Al grain boundary. Phys. Rev. B 2004, 69, 134106. [CrossRef]

12. Lu, G.H.; Zhang, Y.; Deng, S.; Wang, T.; Kohyama, M.; Yamamoto, R.; Liu, F.; Horikawa, K.; Kanno, M. Origin of intergranular embrittlement of $\mathrm{Al}$ alloys induced by Na and Ca segregation: Grain boundary weakening. Phys. Rev. B 2006, 73, 224115. [CrossRef]

13. Zhang, Y.; Lu, G.H.; Wang, T.; Deng, S.; Kohyama, M.; Yamamoto, R. Effects of segregated Ga on an Al grain boundary: A first-principles computational tensile test. Mater. Trans. 2006, 47, 2678-2681. [CrossRef]

14. Yuasa, M.; Mabuchi, M. Bond mobility mechanism in grain boundary embrittlement: First-principles tensile tests of Fe with a P-segregated $\Sigma 3$ grain boundary. Phys. Rev. B 2010, 82, 94108. [CrossRef]

15. Yuasa, M.; Mabuchi, M. Effects of segregated $\mathrm{Cu}$ on an Fe grain boundary by first-principles tensile tests. J. Phys. Condens. Matter 2010, 22, 505705. [CrossRef]

16. Nyyssönen, T.; Isakov, M.; Peura, P.; Kuokkala, V.T. Iterative determination of the orientation relationship between austenite and martensite from a large amount of grain pair misorientations. Metall. Mater. Trans. A 2016, 47, 2587-2590. [CrossRef]

17. Hutchinson, B.; Hagström, J.; Karlsson, O.; Lindell, D.; Tornberg, M.; Lindberg, F.; Thuvander, M. Microstructures and hardness of as-quenched martensites (0.1-0.5\% C). Acta Mater. 2011, 59, 5845-5858. [CrossRef]

18. Ryde, L. Application of EBSD to analysis of microstructures in commercial steels. Mater. Sci. Technol. 2006, 22, 1297-1306. [CrossRef]

19. Razmpoosh, M.H.; Macwan, A.; Biro, E.; Chen, D.L.; Peng, Y.; Goodwin, F.; Zhou, Y. Liquid metal embrittlement in laser beam welding of Zn-coated 22MnB5 steel. Mater. Des. 2018, 155, 375-383. [CrossRef]

20. Martin, S.; Wolf, S.; Martin, U.; Krüger, L.; Rafaja, D. Deformation mechanisms in austenitic TRIP/TWIP steel as a function of temperature. Metall. Mater. Trans. A 2016, 47, 49-58. [CrossRef]

21. Kim, J.; Estrin, Y.; De Cooman, B.C. Application of a dislocation density-based constitutive model to Al-alloyed TWIP steel. Metall. Mater. Trans. A 2013, 44, 4168-4182. [CrossRef]

22. Razmpoosh, M.H.; Biro, E.; Chen, D.L.; Goodwin, F.; Zhou, Y. Liquid metal embrittlement in laser lap joining of TWIP and medium-manganese TRIP steel: The role of stress and grain boundaries. Mater. Charact. 2018, 145, 627-633. [CrossRef]

23. Bhattacharya, D.; Cho, L.; Van der Aa, E.; Ghassemi-Armaki, H.; Pichler, A.; Findley, K.O.; Speer, J.G. Transgranular cracking in a liquid Zn embrittled high strength steel. Scr. Mater. 2020, 175, 49-54. [CrossRef]

24. Li, Y.; Han, C.; Zhang, C.; Jia, K.; Han, P.; Wu, X. Effects of alloying on the behavior of B and S at $\Sigma 5$ (2 10$)$ grain boundary in $\gamma$-Fe Comput. Mater. Sci. 2016, 115, 170-176. [CrossRef]

25. Kresse, G.; Hafner, J. Ab initio molecular dynamics for liquid metals. Phys. Rev. B 1993, 47, 558. [CrossRef]

26. Peng, W.; Peng, H.; Wu, G.; Zhang, J. Effect of zinc-doping on tensile strength of $\Sigma 5$ bcc Fe symmetric tilt grain boundary. Comput. Mater. Sci. 2020, 171, 109204. [CrossRef]

27. Bhattacharya, D.; Cho, L.; Van Der Aa, E.; Pichler, A.; Pottore, N.; Ghassemi-Armaki, H.; Findley, K.O.; Speer, J.G. Influence of the starting microstructure of an advanced high strength steel on the characteristics of Zn-Assisted liquid metal embrittlement. Mater. Sci. Eng. A 2021, 804, 140391. [CrossRef]

28. Cho, L.; Kang, H.; Lee, C.; De Cooman, B.C. Microstructure of liquid metal embrittlement cracks on Zn-coated 22MnB5 press-hardened steel. Scr. Mater. 2014, 90, 25-28. [CrossRef]

29. Kang, H.; Cho, L.; Lee, C.; De Cooman, B.C. Zn penetration in liquid metal embrittled TWIP steel. Metall. Mater. Trans. A 2016, 47, 2885-2905. [CrossRef]

30. Kresse, G.; Furthmüller, J. Efficient iterative schemes for ab initio total-energy calculations using a plane-wave basis set. Phys. Rev. B 1996, 54, 11169. [CrossRef]

31. Perdew, J.P.; Burke, K.; Ernzerhof, M. Generalized gradient approximation made simple. Phys. Rev. Lett. 1996, 77, 3865. [CrossRef] [PubMed]

32. Kresse, G.; Furthmüller, J. Efficiency of ab-initio total energy calculations for metals and semiconductors using a plane-wave basis set. Comput. Mater. Sci. 1996, 6, 15-50. [CrossRef]

33. Ramíarez, R.; Böhm, M.C. Simple geometric generation of special points in brillouin-zone integrations. Two-dimensional bravais lattices. Int. J. Quantum Chem. 1986, 30, 391-411. [CrossRef]

34. Perdew, J.P.; Chevary, J.A.; Vosko, S.H.; Jackson, K.A.; Pederson, M.R.; Singh, D.J.; Fiolhais, C. Atoms, molecules, solids, and surfaces: Applications of the generalized gradient approximation for exchange and correlation. Phys. Rev. B 1992, $46,6671$. [CrossRef] [PubMed]

35. Makov, G.; Shah, R.; Payne, M.C. Periodic boundary conditions in ab initio calculations. II. Brillouin-zone sampling for aperiodic systems. Phys. Rev. B 1996, 53, 15513. [CrossRef] 
36. Blöchl, P.E. Projector augmented-wave method. Phys. Rev. B 1994, 50, 17953. [CrossRef]

37. Monkhorst, H.J.; Pack, J.D. Special points for Brillouin-zone integrations. Phys. Rev. B 1976, 13, 5188. [CrossRef]

38. Basinski, Z.S.; Hume-Rothery, W.; Sutton, A.L. The lattice expansion of iron. Proc. R. Soc. Lond. Ser. A Math. Phys. Sci. 1955, 229, 459-467.

39. Zhang, Y.; Lu, G.-H.; Deng, S.; Wang, T.; Xu, H.; Kohyama, M.; Yamamoto, R. Weakening of an aluminum grain boundary induced by sulfur segregation: A first-principles computational tensile test. Phys. Rev. B 2007, 75, 174101. [CrossRef]

40. Nielsen, O.H.; Martin, R.M. Quantum-mechanical theory of stress and force. Phys. Rev. B 1985, 32, 3780. [CrossRef]

41. Sun, S.N.; Kioussis, N.; Lim, S.P.; Gonis, A.; Gourdin, W.H. Impurity effects on atomic bonding in Ni 3 Al. Phys. Rev. B 1995, 52, 14421. [CrossRef] [PubMed] 